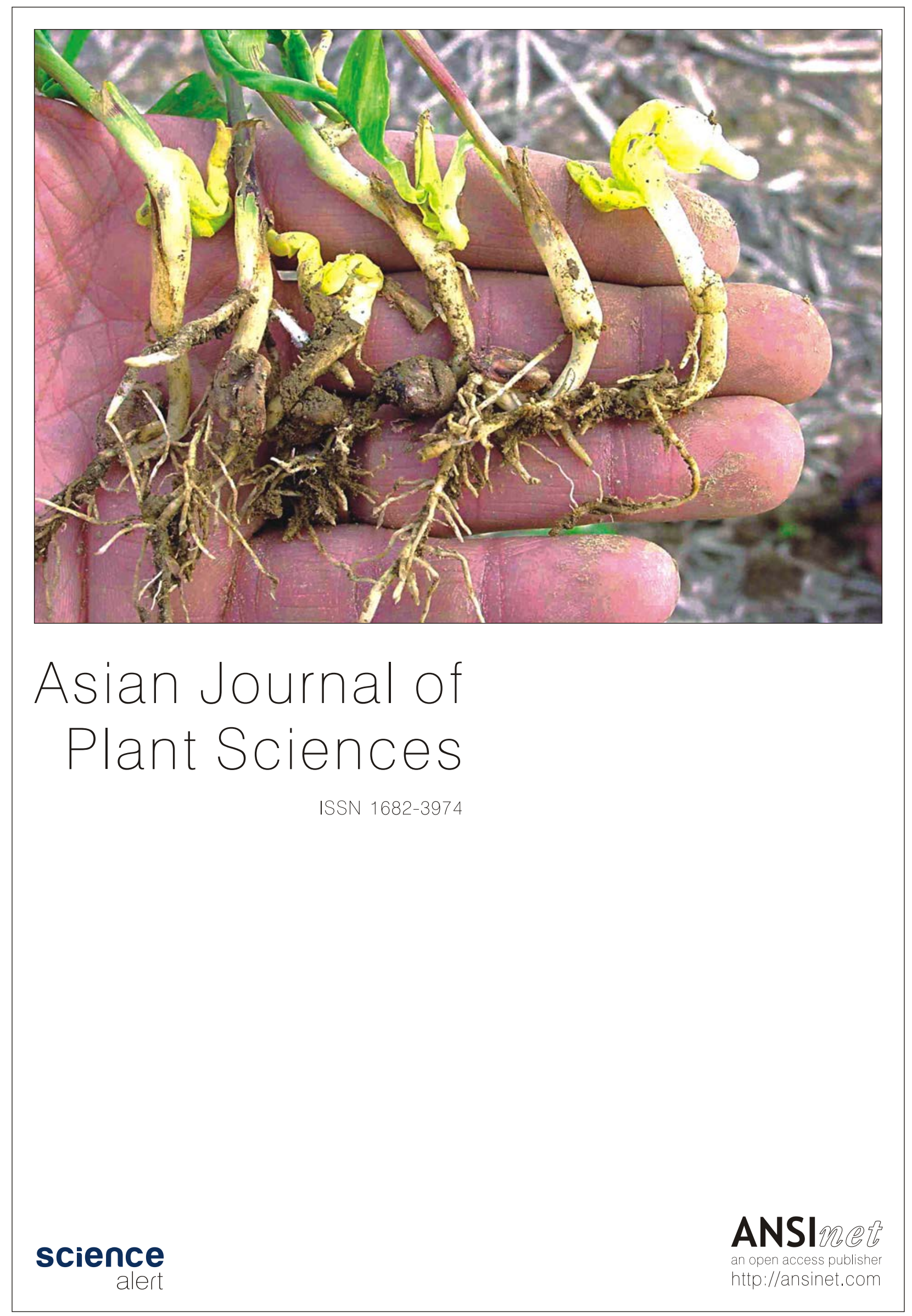




\title{
Improving in vitro Biomass and Evaluating a-glucosidase Inhibition Activity of Liverwort Marchantia polymoprha L.
}

\author{
${ }^{1}$ Tran Quoc Tan, ${ }^{2}$ Phan Ngo Hoang, ${ }^{1}$ Le Ngoc Vy, ${ }^{1}$ Bui Lan Anh, ${ }^{3}$ Duong Tan Nhut and \\ ${ }^{1}$ Quach Ngo Diem Phuong
}

\begin{abstract}
${ }^{1}$ Department of Plant Biotechnology and Biotransformation, University of Science, Vietnam National University, Ho Chi Minh City, Vietnam ${ }^{2}$ Department of Plant Physiology, University of Science, Vietnam National University, Ho Chi Minh City, Vietnam

${ }^{3}$ Tay Nguyen Institute for Scientific Research, Vietnam Academy of Science and Technology, Da Lat, Lam Dong, Vietnam
\end{abstract}

\section{Abstract}

Background and Objective: Marchantia polymorpha L. has been used in traditional medicine of some countries. Harvesting of bryophytes in nature, including M. polymorpha, is difficult to ensure sufficient biomass for research and treatment purposes. Therefore, cultivation in vitro liverwort was conducted to take initiative in collecting biomass. Materials and Methods: Sterilized spores of liverwort were cultured on modified Gamborg-B5 medium with BA, kinetin or coconut water to form thallus. New thallus was investigated for biomass growth with different factors including culture mediums (Gamborg-B5, Murashige-Skoog, white), sugar (sucrose, glucose), light types (fluorescent, blue LED $454 \mathrm{~nm}$, red LED $660 \mathrm{~nm}$ ), tryptone and cultivation substrates (agar, liquid medium with cotton swabs, with/without 90 rpm shaker). Finally, the $\alpha$-glucosidase inhibition activity of cultured biomass was investigated. Results: On Gamborg-B5 medium with BA $0.5 \mathrm{mg} \mathrm{L}^{-1}$, new thallus regenerated on explants with high regeneration rate and a higher number of sheets per explant than the other treatments. When combined the suitable conditions, the dry biomass was significantly improved and increased by 1.62 times compared to control-initial culture conditions. Moreover, $\alpha$-glucosidase inhibition activity of $n$-hexane, chloroform, ethyl acetate and ethanol extracts of the liverwort from modified process was stronger than positive control-Acarbose. The $\mathrm{n}$-hexane fraction $\left(\mathrm{IC}_{50}=11.89 \mu \mathrm{g} \mathrm{mL} \mathrm{m}^{-1}\right) \mathrm{was}$ remarkable and stronger than acarbose approximately 44 times. Conclusion: M. polymorpha biomass can be obtained through in vitro culture as a raw material source for studies on the biologically active and secondary metabolites. The cultured biomass also shows potential compounds in $\alpha$-glucosidase inhibitory activity.

Key words: Biomass, bryophytes, in vitro culture, liverwort, Marchantia polymorpha L., $\alpha$-glucosidase inhibition activity

Citation: Tran Quoc Tan, Phan Ngo Hoang, Le Ngoc Vy, Bui Lan Anh, Duong Tan Nhut and Quach Ngo Diem Phuong, 2020. Improving in vitro biomass and evaluating $\alpha$-glucosidase inhibition activity of liverwort Marchantia polymoprha L. Asian J. Plant Sci., 19: 133-145.

Corresponding Author: Quach Ngo Diem Phuong, Department of Plant Biotechnology and Biotransformation, University of Science, Vietnam National University, Ho Chi Minh City, Vietnam

Copyright: @ 2020 Tran Quoc Tan et al. This is an open access article distributed under the terms of the creative commons attribution License, which permits unrestricted use, distribution and reproduction in any medium, provided the original author and source are credited.

Competing Interest: The authors have declared that no competing interest exists. 


\section{INTRODUCTION}

At present, non-vascular plants (Bryophytes) are divided into three phyla: liverworts-Marchantiophyta, hornworts-Anthocerotophyta and moss-Bryophyta'. These plants are small, lignin-free, without vascular structures and whole plant is fragile cell layers. They do not have many mechanical protections as in vascular plants'. However, bryophytes have special, simple and effective secondary metabolites to help them survive the effects of the external environment. As a result, the research of secondary compounds of non-vascular plants becomes interesting and highly regarded.

Currently, scientific records show that bryophytes have been known to use in serving daily activities and treating some diseases according to folklore experience for a long time $^{2}$. For instance, some tribes in China have used moss to treat heart, eye and skin diseases. In India, liverworts are used to treat liver-related diseases, inflammation and venomous snakebites ${ }^{1-3}$. This evidence suggests that non-vascular plants could contain the great number of active ingredients that need to be scientifically and systematically investigated ${ }^{1,4}$. In Southeast Asia area, the humid climate is a favorable condition for growth, especially the liverwort, these species here are intensely diverse but mixed with many types belonging to the Lejeuneaceae ${ }^{5}$. It leads to consume much time for selection to purify wild collected samples. Another feature related to development of these plants is slow growth rate in the wild that is also a difficulty in obtaining uninterrupted amounts of biomass ${ }^{6}$. Therefore, bryophytes cultivation is essential to provide a sufficiently large amount of raw material for serving the active substance studies and limiting some of the obstacles of harvesting in the wild (e.g., time, geography, weather, etc.).

Marchantia polymorpha is one of the largest thalloid liverworts in the world ${ }^{3,7}$. This liverwort usually distributes in high mountainous areas, wet and temperate areas and grows into dense mats ${ }^{8}$. In traditional medicine of India, China, some European countries and Himalayan people, M. polymorpha has been used to treat diuretic activity and cure cuts, fractures, snake bites, burns and open wounds ${ }^{2,8}$. It is found in oil bodies-a special organelle of this species containing volatile compounds such as thujopsene, $\beta$-chamigrene, etc. and the specific phenolic compounds of the bis(bibenzyl) group ${ }^{9,10}$. In particular, the compounds of the bisbibenzyl group, represented by the marchantin $A$, have many remarkable biological activities such as anti-proliferation of cancer cell lines, antibacterial, antifungal, muscle relaxant activity, etc. ${ }^{13,11}$. In addition, the analysis of the active substance also shows a difference in the composition of marchantin types and their content in M. polymorpha growing in different geographical areas, this shows that the soil and climate conditions have impacts on the path of metabolism of this geographical species $^{12}$. It is essential for the full exploitation of the potential compounds found in the Marchantia polymorpha, especially in Vietnam, where the information of biological activities and compounds of this species is rather limited in both folklore records and scientific analysis.

This study focused on increasing the biomass of $M$. polymorpha by investigating the effects of cytokinin (6-benzyladenine, kinetin) or coconut water on the morphogenesis of explants from the thallus and then, culturing in in vitro conditions.

\section{MATERIALS AND METHODS}

Study area: Marchantia polymorpha was collected at Nam Thien ward, Dalat city, Lam Dong province, Vietnam from May, 2017 to June, 2017. The related experiments were conducted from July, 2017 to February, 2019 at Plant Biotechnology Laboratory of Department of Plant Physiology, University of Science, Vietnam National University of Ho Chi Minh City, Ho Chi Minh City, Vietnam.

Materials: Marchantia polymorpha samples were identified and authenticated by Department of Ecology and Evolutionary Biology, Faculty of Biology, University of Science, National University-Ho Chi Minh city. Unbroken mature yellow sporangia of Marchantia polymorpha were obtained and stored in micro-tubes at cool temperature $\left(4 \pm 1^{\circ} \mathrm{C}\right)$ for surface-sterilizing.

\section{Sterilization and primary culture conditions}

Sporangia sterilization: Surface-sterilization of M. polymorpha process was performed with solution containing sodium hypochlorite $0.2 \%$ and Tween $200.1 \%$ as described in previous study by Chiyoda et al. ${ }^{13}$. Sporangium stored in micro-tube was washed with distilled water in 3-5 times and then incubated in sterilization solution for $5 \mathrm{~min}$. After that, sporangium was washed with 3-5 times with sterile water using micro-pipette to remove sterilizing solution.

Sporangia were broken in $200 \mu \mathrm{L}$ sterile water per sporangium and suspended thoroughly by micropipette. Spore was cultured at the rate of $50 \mu \mathrm{L}$ spore suspension in $20 \mathrm{~mL}$ liquid culture medium, on shaker with $90 \mathrm{rpm}$. After 7 days, the cultured spore suspension was spread onto solid culture medium in a petri dish. Thallus developed from spores after at least 45 days. 
Culture conditions: Culture medium referred from reports of Ishizaki et al. ${ }^{14}$ with slight modifications included: Half-strength salts and vitamins of Gamborg-B5 medium ${ }^{15}$ added $10 \mathrm{~g} \mathrm{~L}^{-1}$ sucrose, $1 \mathrm{~g} \mathrm{~L}^{-1}$ tryptone, $10 \mathrm{~g} \mathrm{~L}^{-1}$ agar (for solid medium), pH adjusted to $5.5 \pm 0.1$ before autoclaved at $121^{\circ} \mathrm{C}, 1 \mathrm{~atm}$ for $20 \mathrm{~min}$. Liverwort cultured in vitro was illuminated at $16 \mathrm{~h} /$ day by white fluorescent lamps, with an illumination intensity of approximately 2000 lux. The temperature of the culture room was $25 \pm 2^{\circ} \mathrm{C}$ and the humidity was $70-75 \%$.

Effect of cytokinins and coconut water on generation of explants from mature thallus: Sheets of mature thalli (4-5 mm in diameter) removed apical notches were cut into small explants (thin slices with 1-2 mm in width). Explants were placed on solid half-strength B5 supplemented with cytokinins including $B A\left(0.5,1.0,3.0\right.$ and $\left.5.0 \mathrm{mg} \mathrm{L}^{-1}\right)$ or Kinetin $\left(0.5,1.0,3.0\right.$ and $\left.5.0 \mathrm{mg} \mathrm{L}^{-1}\right)$ or coconut water (5 and $10 \%$ $(\mathrm{v} / \mathrm{v}))$. Medium without plant growth regulators or coconut water is negative control treatment. Each petri dish of culture medium contained 10-11 explants, four replications for each treatment. After 3 weeks, morphological differences and survival rate (\%) of explants were recorded.

\section{Effects of five independent culture factors on thallus}

biomass: Five experiments were set up for investigation of five independent culture factors. Firstly, the experiment was conducted to investigate the effectives of the some medium such as full, half (1/2), quarter (1/4)-strength of Gamborg-B5 or Murashige-Skoog or full, half (1/2)-strength of white on the growth of thallus ${ }^{15-17}$. Secondly, the experiment was designed to evaluate the type of sugar (sucrose or glucose) with concentration ranges $\left(0,10,20\right.$ and $\left.30 \mathrm{~g} \mathrm{~L}^{-1}\right)$ added in medium for increasing the biomass of thallus. Thirdly, the experiment was carried out with different light types including fluorescent light, blue LED $454 \mathrm{~nm}$ (2300 lux), red LED $660 \mathrm{~nm}$ (2300 lux) and dark. Next, the fourthly experiment was conducted to evaluate the effect of different concentrations of tryptone $\left(0,0.1,0.5,1.0,1.5 \mathrm{~g} \mathrm{~L}^{-1}\right)$ in the medium on the biomass accumulation of thallus. Finally, the experiment of cultivation substrate types (such as solid medium, liquid medium or in liquid medium with $90 \mathrm{rpm}$ shaker, liquid medium with cotton swabs) was organized to select suitable treatments to increase the fresh and dry biomass of clusters.

In all experiments, the initial samples were thallus with 3-4 sheets of thalli induced for 2 weeks in culture medium supplemented plant growth regulator which was selected from investigation of effectives of plant growth regulators experiment. Four to five thalli (0.2-0.3 $\mathrm{g}$ of fresh weight) were placed on a petri dish containing $30 \mathrm{~mL}$ medium as a replication. In investigation of cultivation substrates, the thallus was placed in $500 \mathrm{~mL}$ glass bottles. Each experiment was performance with three replications. After 6 weeks of cultivation, the fresh and dry weight $(\mathrm{g})$ per petri dish or bottle was collected.

\section{Combination of independent culture factors and evaluation} of biomass increase: The experiment was conducted to compare the accumulation of thallus biomass of the primary culture conditions (control) and the modified medium (combining the independent improved culture factors which increase the largest biomass). The experiment was carried out in $500 \mathrm{~mL}$ glass bottles containing $30 \mathrm{~mL}$ of medium and 4 thalli in a bottle. The experiment was monitored for 7 weeks, the fresh and dry weight per a culture bottle was weekly collected and the curve of growth index (Gl) was calculated by the following formula:

$$
\mathrm{GI}=\frac{\mathrm{W}_{\mathrm{i}}-\mathrm{W}_{0}}{\mathrm{~W}_{0}}
$$

In which, $\mathrm{W}_{\mathrm{i}}$ and $\mathrm{W}_{0}$ were biomass (fresh or dry weight) of all thallus in a bottle at the time of collection and at the baseline, respectively ${ }^{18}$.

Extraction for $\alpha$-glucosidase analysis: Thallus of M. polymorpha L. were cultured for 7 weeks in the modified process, which was able to increase the biomass higher than that of the primary process, harvested, washed several times with tap water and dried at $48^{\circ} \mathrm{C}$ to constant volume. Samples are crushed by grinding and soaked in solvents by maceration method $^{19}$. First, the sample was soaked and extracted several times (24 h/time) with $\mathrm{n}$-hexane until the sample was extracted to exhaustion. Next, n-hexane is replaced by solvents in increasing polarity: Chloroform, ethyl acetate and ethanol as finale. The extract solutions of one solvent was collected and evaporated under reduced pressure to obtain four fractional extracts.

$\alpha$-glucosidase inhibition activity assay: The assay was performance in 96-well microtiter plate as previously described with slight modifications ${ }^{20}$. Each well contained $50 \mu \mathrm{L}$ of solution of sample diluted in sodium phosphate buffer $100 \mathrm{mM}$ (pH 6.8, 5\% DMSO) and $40 \mu \mathrm{L}$ solution of $\alpha$-glucosidase (Sigma) $0.2 \mathrm{U} \mathrm{mL}^{-1}$, the mixture was incubated at room temperature for $20 \mathrm{~min}$. Then, the mixture was added 
$40 \mu \mathrm{L}$ of $\mathrm{p}-\mathrm{NPG} 5 \mathrm{mM}$ as a substrate and incubated for $20 \mathrm{~min}$. Finally, $130 \mu \mathrm{L}$ of $\mathrm{Na}_{2} \mathrm{CO}_{3} 0.2 \mathrm{M}$ was placed in the well to stop the reaction before measuring OD $405 \mathrm{~nm}$ by Perkin Elmer 2030 Elisa reader. The reaction mixture not added enzyme is blank. Acarbose was used as a positive control. Buffer used for dissolving the extracts is negative control. Each sample was tested with 3 replicates. The percentage of inhibition activity (\%l) was calculated according to the equation:

$$
\mathrm{I}(\%)=\frac{1-\left(\mathrm{OD}_{\mathrm{s}}-\mathrm{OD}_{\mathrm{BS}}\right)}{\mathrm{OD}_{\mathrm{NC}}-\mathrm{OD}_{\mathrm{BNC}}} \times 100
$$

$\mathrm{OD}_{\mathrm{S}}$ and $\mathrm{OD}_{\mathrm{BS}} \quad=$ Optical density of sample and sample blank

$\mathrm{OD}_{\mathrm{NC}}$ and $\mathrm{OD}_{\mathrm{BNC}}=$ Optical density of negative control and blank of negative control

Statistical analysis: All data were analyzed by SPSS version 16.0 (IBM SPSS Inc.) and Microsoft Excel 2010 (Microsoft Software). Experimental results were represented as mean \pm standard deviation (SD). Differences between means were evaluated by Duncan's multiple range tests. The statistically significant difference was accepted at a level of $\mathrm{p}<0.05$.

\section{RESULTS AND DISCUSSION}

Sterilization and development of spores: The sporangium is sterilized to create the initial sample source for culturing process. The spores developed favorably in liquid medium and formed protonemata after 7 days of culture (Fig. 1a, b). The results showed that the sterilization process using sodium hypochlorite $0.2 \%$ for $5 \mathrm{~min}$ did not affect spores in the sporangium.

After 7 days of cultured on shaker, protonemata (Fig. 1c) were spread onto a solid culture medium to continue development. Sporeling (Fig. 1d) developed from protonemata after 15 days. After 20 days from the sporeling appear, the immature thallus (Fig. 1e) was formed. In M. polymorpha L. liverwort, the sporangia have many advantages for disinfection of the input material as it has the large number of spores (approximately $1 \times 10^{5}$ spores/sporangium) ${ }^{13}$ and a coating that avoids the effect of the sterilization solutions on the spores. However, further testing of other sterilization procedures should be carried out for different materials such as fresh thalli, gemmae, etc.

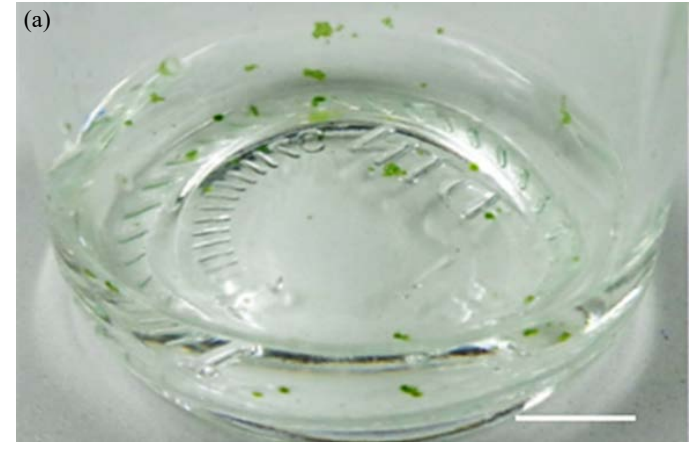

(c)

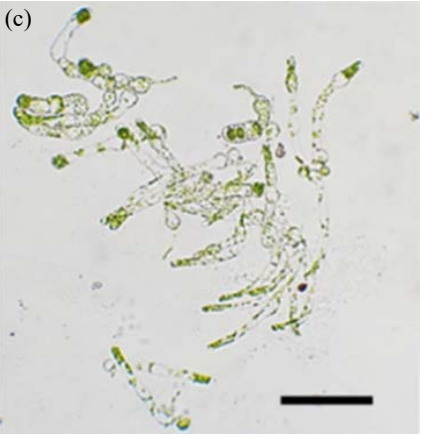

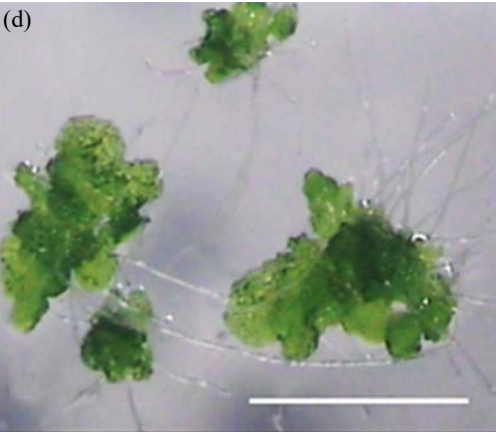

(d)

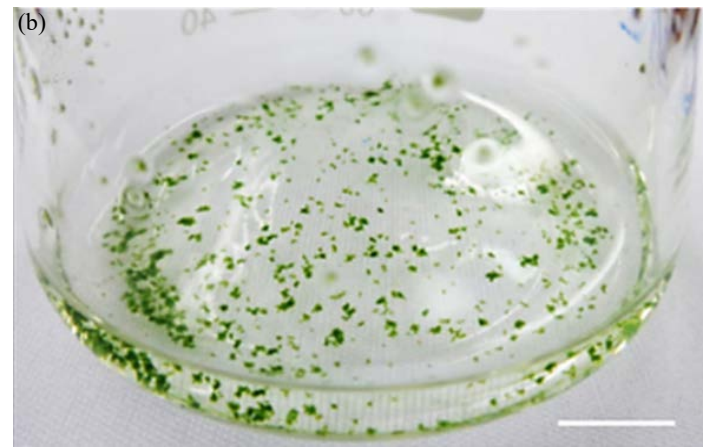

(e)

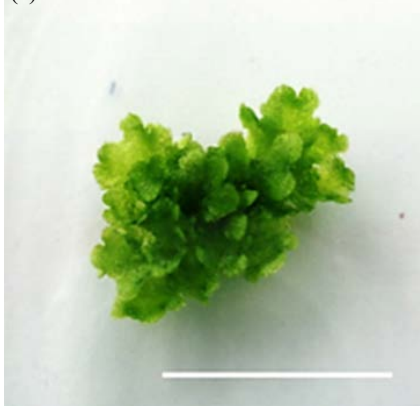

Fig. 1(a-e): Spores developed well in the liquid culture medium after the sterilization process, (a) Spores developed after 4 days of culture, (b) After 7 days, (c) Protonemata developed from spores that were observed under the microscope, (d) Sporeling developed from protonemata after 15 days and (e) 35-days immature thallus derived from sporeling Bar: a, b, e: 1 cm, c: $200 \mu \mathrm{m}$, d: $500 \mu \mathrm{m}$ 
Asian J. Plant Sci., 19 (2): 133-145, 2020

\begin{tabular}{|c|c|c|c|c|}
\hline $\begin{array}{l}\text { Cytokinin or } \\
\text { coconut water }\end{array}$ & $\begin{array}{c}\text { Concentration }\left(\mathrm{mg} \mathrm{L}^{-1}\right) \\
\text { or }(\mathrm{v} / \mathrm{v} \%)\end{array}$ & $\begin{array}{c}\text { Ratio of explants created } \\
\text { new thallus/total explants (\%) }\end{array}$ & $\begin{array}{l}\text { Average number of } \\
\text { thalli sheets/explant }\end{array}$ & $\begin{array}{c}\text { Area of } \\
\text { thalli }\left(\mathrm{cm}^{2}\right)\end{array}$ \\
\hline$\overline{\text { Control }}$ & & $93.87 \pm 6.25^{\mathrm{ab}}$ & $12.00 \pm 3.00^{\mathrm{ab}}$ & $0.15 \pm 0.03^{d}$ \\
\hline \multirow[t]{4}{*}{ BA-6-Benzyladenine } & 0.5 & $97.78 \pm 3.85^{\mathrm{a}}$ & $16.67 \pm 1.53^{\mathrm{a}}$ & $0.2 \pm 0.03^{\mathrm{cd}}$ \\
\hline & 1.0 & $92.86 \pm 12.37^{\mathrm{ab}}$ & $13.00 \pm 1.73^{\mathrm{ab}}$ & $0.2 \pm 0.05^{\mathrm{bcd}}$ \\
\hline & 3.0 & $100.00 \pm 0.00^{\mathrm{a}}$ & $12.33 \pm 2.08^{\mathrm{ab}}$ & $0.26 \pm 0.05^{b c}$ \\
\hline & 5.0 & $82.41 \pm 8.02^{b}$ & $12.67 \pm 3.21^{\mathrm{ab}}$ & $0.34 \pm 0.10^{\mathrm{a}}$ \\
\hline \multirow[t]{4}{*}{ Kinetin } & 0.5 & $95.21 \pm 4.18^{a}$ & $14.67 \pm 1.53^{\mathrm{ab}}$ & $0.28 \pm 0.03^{\mathrm{ab}}$ \\
\hline & 1.0 & $94.44 \pm 9.62^{\mathrm{a}}$ & $14.00 \pm 2.65^{\mathrm{ab}}$ & $0.25 \pm 0.02^{\mathrm{bc}}$ \\
\hline & 3.0 & $92.22 \pm 8.39^{\mathrm{ab}}$ & $10.67 \pm 2.08^{b}$ & $0.24 \pm 0.02^{\mathrm{bc}}$ \\
\hline & 5.0 & $100.00 \pm 0.00^{\mathrm{a}}$ & $11.67 \pm 2.08^{\mathrm{ab}}$ & $0.24 \pm 0.02^{\mathrm{bc}}$ \\
\hline \multirow[t]{2}{*}{ Coconut water } & $5 \%$ & $100.00 \pm 0.00^{\mathrm{a}}$ & $11.00 \pm 2.00^{\mathrm{ab}}$ & $0.21 \pm 0.01^{\mathrm{bcd}}$ \\
\hline & $10 \%$ & $100.00 \pm 0.00^{\mathrm{a}}$ & $16.00 \pm 7.00^{\mathrm{ab}}$ & $0.34 \pm 0.01^{\mathrm{a}}$ \\
\hline
\end{tabular}

Different letters in one column presents significant differences at the level of $p<0.05$

Morphogenesis of explants from mature thallus on medium propagation of vascular plants, plant growth regulators as cytokinin are usually added to the medium to help cultured samples generating increase the number of shoots, thereby increasing the number of seedling ${ }^{21}$. In the M. polymorpha, the body is simply composed of thalli sheets. Therefore, the experiment was conducted to investigate the formation of new thallus from thin explants cut from mature thallus.

Results recorded through observation showed that most of the explants were survived and formed clusters of new sheets of thalli on the medium supplemented cytokinins or coconut water. Thus, the suitable supplements with appropriate concentrations were selected based on 3 criteria: The ratio of the sample explants created new thallus on total sample/petri dish (\%), the number averaged of thalli sheets/1 explant (sheets/explant), area average of thalli $\left(\mathrm{cm}^{2}\right)$.

The results of the three criteria are presented in Table 1 and Fig. 2. In the criterion of the ratio of explants created new thallus on total sample (per petri dish), BA $\left(0.5\right.$ and $\left.3 \mathrm{mg} \mathrm{L}^{-1}\right)$, kinetin $\left(0.5,1\right.$ and $5 \mathrm{mg} \mathrm{L}^{-1}$ ) and coconut water (5 and 10\%) treatments gave better rate than other treatments, the rate ranged from $94.44-100 \%$ and no differences were statistically significant. In the number of thalli sheets/explant, BA $0.5 \mathrm{mg} \mathrm{L}^{-1}$ induced better than other treatments, with the average number of sheets per explant was 16.67. The largest average area of thalli $\left(0.34 \mathrm{~cm}^{2}\right)$ belonged to $B A 5 \mathrm{mg} \mathrm{L}^{-1}$ and $10 \%$ of coconut water treatments.

The results showed that $10 \%$ coconut water added to the culture medium, induced with the highest rate of thallus formation and the largest area of thalli. The average number of thalli sheets/slice was 16 and was approximately equal to that of BA $0.5 \mathrm{mg} \mathrm{L}^{-1}$. In nature, coconut water has lots of ingredients depending on the type of coconut and the development time of fruit. However, coconut water has been shown to be a suitable material for plant tissue culture on an industrial scale because it is completely natural, has no chemical residues, is easy to obtain and is cheaper than cytokinins. The results confirmed again the effect of coconut on morphogenesis of explants from mature thallus and showed that it will be the appropriate choice in using for industrial production.

However, due to the accuracy of composition and absolute stability, BA concentration of $0.5 \mathrm{mg} \mathrm{L}^{-1}$ in the medium was selected for further experiments in this study. Although BA $5 \mathrm{mg} \mathrm{L}^{-1}$ gave the highest area of thalli, the use of high concentration of plant hormones could regulates the instability and mutation of the sample ${ }^{22,23}$. On the other hand, in in vitro culture, BA is more commonly used than Kinetin because of its higher activity in morphological induction and lower cost.

\section{Effect of salts and vitamins of some cultured medium on} growth of thallus biomass: After being induced on medium supplemented with BA $0.5 \mathrm{mg} \mathrm{L}^{-1}$, thallus was investigated for biomass growth under different culture conditions. Table 2 presents the results of the influence of mineral and vitamin complexes on fresh and dry biomass of thallus.

The results in Table 2 show that the Gamborg-B5 (B5) medium group had a higher dry biomass than the Murashige and Skoog (MS) and White (W) group. In addition, in the B5 group, the fresh biomass of the 1/4 B5 treatments was lower than the two remaining treatments.

Morphological observations show that, in treatments B5 and $1 / 2 \mathrm{~B} 5$, the clusters of $M$. polymorpha developed well with wide thallus and many gemmae-cups. Meanwhile, $1 / 4 \mathrm{~B} 5$ treatment had biomass equivalent to the above 2 treatments, but the thallus did not develop well with the yellowish-brown edge of thalli sheets (Fig. 3). In the MS and White medium group, thallus was unfavorable and clustered. In particular, the White medium with low nutrient content caused the stressed clusters to exhibit signs of developmental instability, small area and large yellow surface of thalli sheets. 


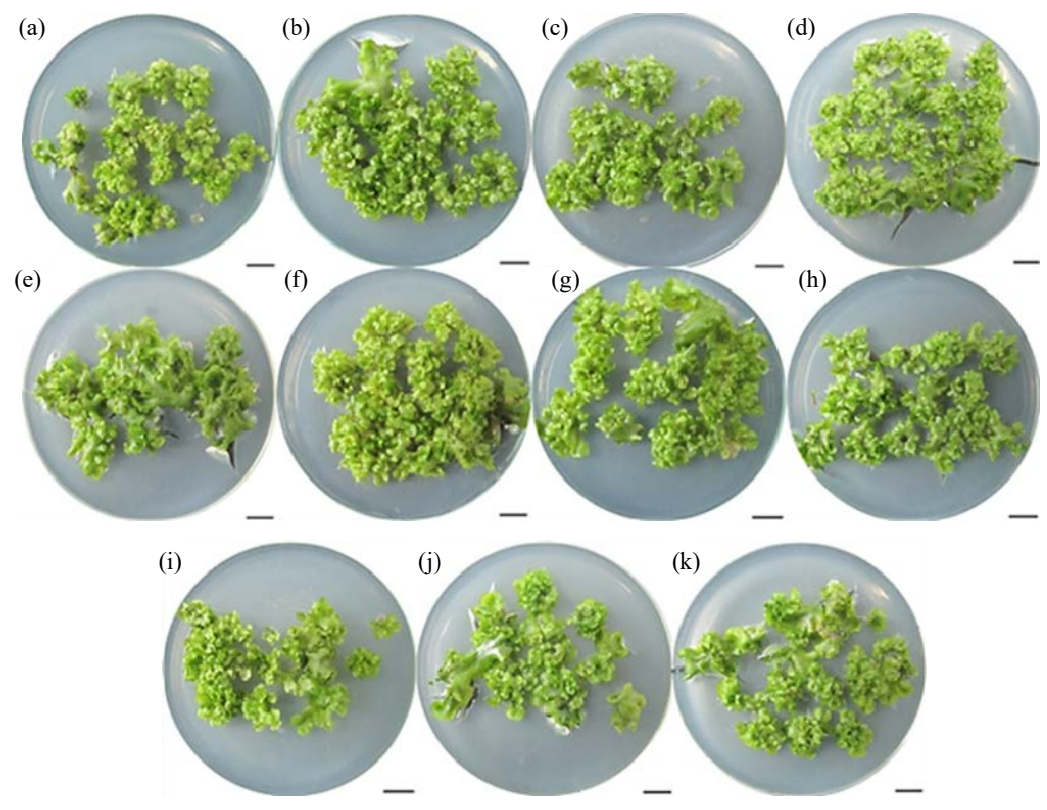

Fig. 2(a-e): Slices were induced on different mediums after 3 weeks of culture, (a) Control and (b-e) Medium supplemented BA with a concentration of $0.5,1,3,5 \mathrm{mg} \mathrm{L}^{-1},(\mathrm{f}-\mathrm{i})$ Medium supplemented Kinetin with a concentration of $0.5,1,3,5 \mathrm{mg} \mathrm{L}^{-1}$ and $(\mathrm{j}-\mathrm{k})$ Medium supplemented coconut water at $5,10 \%(\mathrm{v} / \mathrm{v})$ Bars: $1 \mathrm{~cm}$

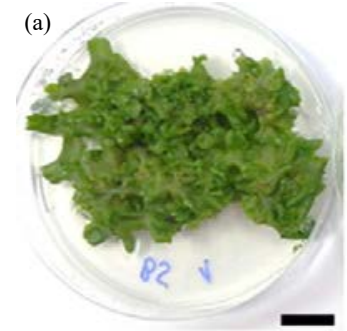

(d)

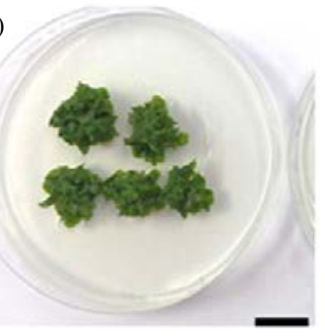

(g)

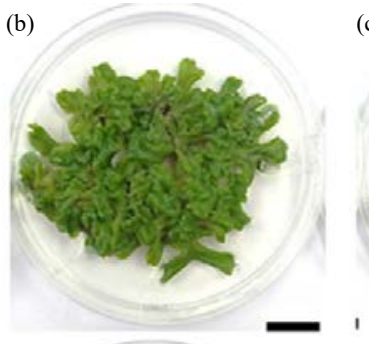

(e)

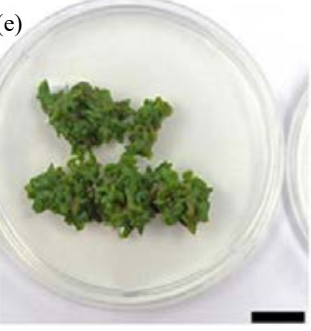

(h)

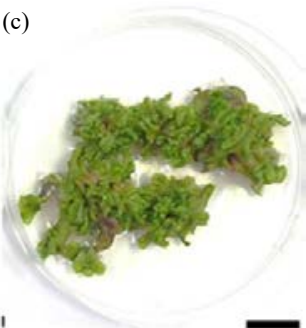

(f)

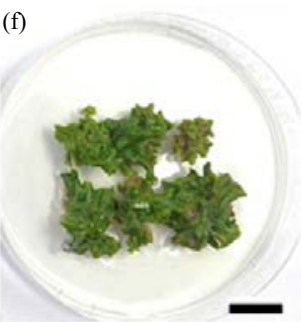

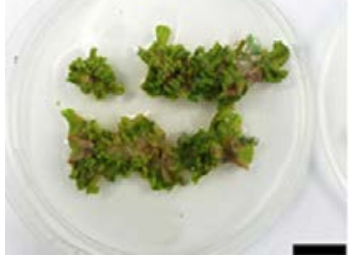

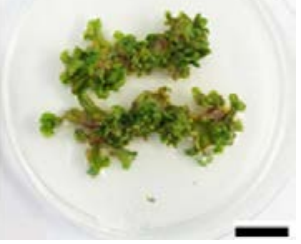

Fig. 3(a-h): Development of thallus on different salts and vitamin complexes of cultivation mediums, (a-c) Gamborg's B5 medium with full, a half and a quarter of salts and vitamins, (d-f) Murashige and Skoog medium with full, a half and a quarter of salts and vitamins and ( $\mathrm{g}-\mathrm{h})$ White medium with full and a half of salts and vitamins Bars: $2 \mathrm{~cm}$ 


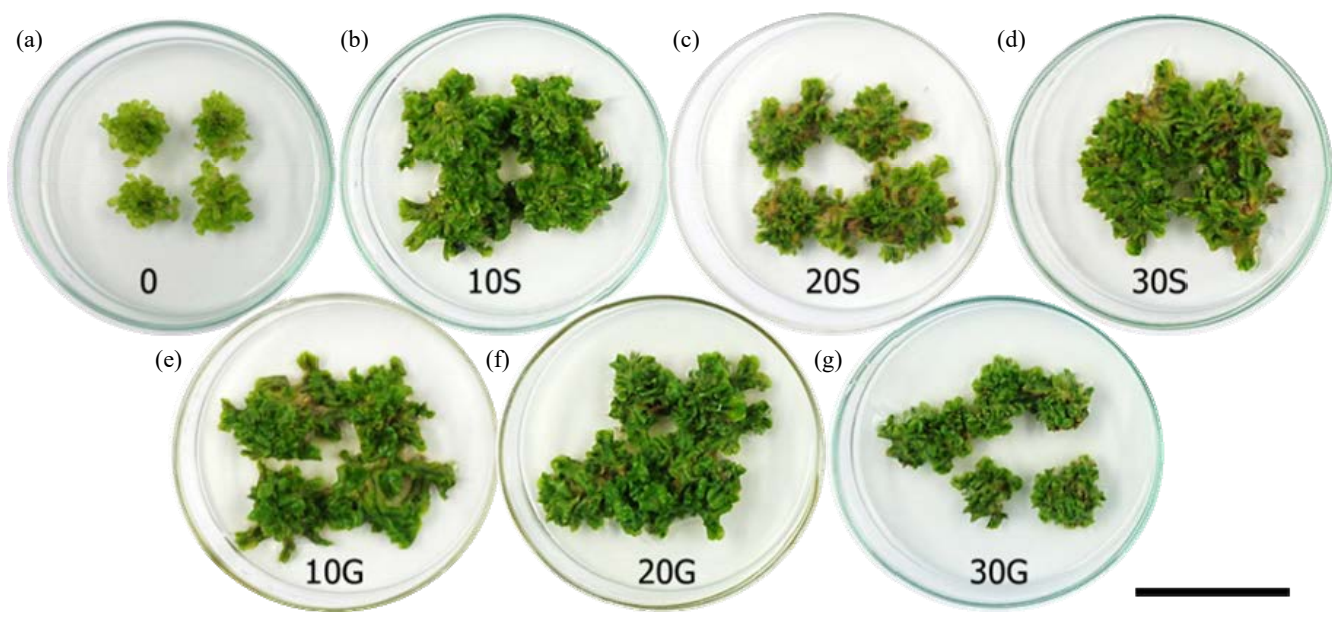

Fig. 4(a-b): Thallus developed on cultured medium (a) Without sugar (0), (b-d) Sucrose (S) and (e-g) Glucose (G) supplementation with concentrations of 10,20 and $30 \mathrm{~g} \mathrm{~L}^{-1}$

Bar: $5 \mathrm{~cm}$

Table 2: Effect of different mineral and vitamin complexes of cultivation medium on the biomass of Marchantia polymorpha L.

\begin{tabular}{lcc}
\hline $\begin{array}{l}\text { Mineral and vitamin } \\
\text { complexes of medium }\end{array}$ & $\begin{array}{c}\text { Fresh weight } \\
\text { of biomass }(\mathrm{g})\end{array}$ & $\begin{array}{c}\text { Dry } \\
\text { weight }(\mathrm{g})\end{array}$ \\
\hline B5 (Gamborg's B5) & $9.74 \pm 0.41^{\mathrm{a}}$ & $0.29 \pm 0.01^{\mathrm{a}}$ \\
1/2B5 & $10.86 \pm 1.46^{\mathrm{a}}$ & $0.29 \pm 0.03^{\mathrm{a}}$ \\
1/4B5 & $7.96 \pm 0.72^{\mathrm{b}}$ & $0.29 \pm 0.03^{\mathrm{a}}$ \\
MS (Murashige and Skoog) & $3.75 \pm 0.54^{\mathrm{c}}$ & $0.22 \pm 0.03^{\mathrm{b}}$ \\
1/2MS & $3.69 \pm 0.17^{\mathrm{c}}$ & $0.21 \pm 0.01^{\mathrm{b}}$ \\
1/4MS & $3.80 \pm 0.10^{\mathrm{c}}$ & $0.20 \pm 0.02^{\mathrm{b}}$ \\
W (White) & $2.38 \pm 0.41^{\mathrm{de}}$ & $0.14 \pm 0.02^{\mathrm{cd}}$ \\
1/2W & $2.95 \pm 0.36^{\mathrm{d}}$ & $0.15 \pm 0.02^{\mathrm{c}}$ \\
\hline
\end{tabular}

Different letters in one column presents significant differences at the level of $p<0.05$

Table 3: Fresh and dry biomass of M. polymorpha L. for different types of sugar and concentrations

\begin{tabular}{lcr}
\hline Type-concentration $\left(\mathrm{g} \mathrm{L}^{-1}\right)$ & Fresh weight $(\mathrm{g})$ & Dry weight $(\mathrm{g})$ \\
\hline 0 & $1.11 \pm 0.10^{\mathrm{e}}$ & $0.03 \pm 0.00^{\mathrm{d}}$ \\
Sucrose-10 & $7.41 \pm 0.28^{\mathrm{cd}}$ & $0.27 \pm 0.01^{\mathrm{c}}$ \\
Sucrose-20 & $11.40 \pm 1.12^{\mathrm{a}}$ & $0.50 \pm 0.04^{\mathrm{a}}$ \\
Sucrose-30 & $8.18 \pm 1.04^{\mathrm{bc}}$ & $0.37 \pm 0.04^{\mathrm{b}}$ \\
Glucose-10 & $6.54 \pm 1.26^{\mathrm{cd}}$ & $0.24 \pm 0.03^{\mathrm{c}}$ \\
Glucose-20 & $9.27 \pm 1.51^{\mathrm{b}}$ & $0.38 \pm 0.06^{\mathrm{b}}$ \\
Glucose-30 & $5.85 \pm 0.56^{\mathrm{d}}$ & $0.30 \pm 0.02^{\mathrm{c}}$ \\
\hline Different letters in one column presents significant differences at the level of \\
$\mathrm{p}<0.05$
\end{tabular}

The M. polymorpha liverwort developed well in culture medium with high $\mathrm{NO}_{3}{ }^{-}$concentration ${ }^{24}$. In this experiment, MS and $\mathrm{B} 5$ were two groups of medium with high $\mathrm{NO}_{3}{ }^{-}$level with corresponding content of $39.4 \mathrm{mM}$ and $25.0 \mathrm{mM}$, respectively. In addition, the ratio of $\mathrm{NO}_{3}{ }^{-} / \mathrm{NH}_{4}{ }^{+}$is a factor to be considered, which reflects the type of nitrogen-containing ion that the plant prefers to absorb ${ }^{21,25,26}$. The $\mathrm{B} 5$ group medium have a much higher $\mathrm{NO}_{3}{ }^{-} / \mathrm{NH}_{4}{ }^{+}$ratio than the MS medium, with 12.5 of $\mathrm{B} 5$ and 1.91 of MS. In addition, this rate does not change between $\mathrm{B} 5$ and $1 / 2 \mathrm{~B} 5$. The biomass results showed no difference between $B 5$ and $1 / 2$ B5 treatments. In addition, the vitamin content of the B5 medium group was also higher than that of the other medium ${ }^{15,21}$. These characteristics may make the thallus biomass in this group higher than the MS and White treatments. Half-strength B5 was selected because of its reduced mineral and vitamin content but increases the biomass and promotes growth of thallus (Fig. 4).

Effect of type and concentration of sugar in medium: Sugar is added to the culture medium that supports growth and carbohydrate synthesis of in vitro plants. Each type of plant is capable of absorbing and using sugars with different demands and types. Therefore, the experiment was carried out to investigate and select the appropriate sugar types and concentrations for the biomass increase of the in vitro M. polymorpha. Results showed that sucrose supplemented with $20 \mathrm{~g} \mathrm{~L}^{-1}$ culture medium was the suitable condition for in vitro culture of M. polymorpha to obtain biomass.

Results of fresh and dry biomass in Table 3 showed that sucrose at the concentration of $20 \mathrm{mg} \mathrm{L}^{-1}$ gave the highest biomass in the treatments, with fresh and dry biomass of 11.4 and $0.5 \mathrm{~g}$, respectively. At the same concentration, the fresh and dried biomass in the sucrose supplementation was higher than that of glucose, suggesting that the plant absorbed and metabolized sucrose for biomass accumulation better than glucose. When marking ${ }^{14} \mathrm{C}$ for sucrose molecules and observing their transport in the M. polymorpha, Rota and Maravolo ${ }^{27}$ found that sucrose moves between cells, specially 


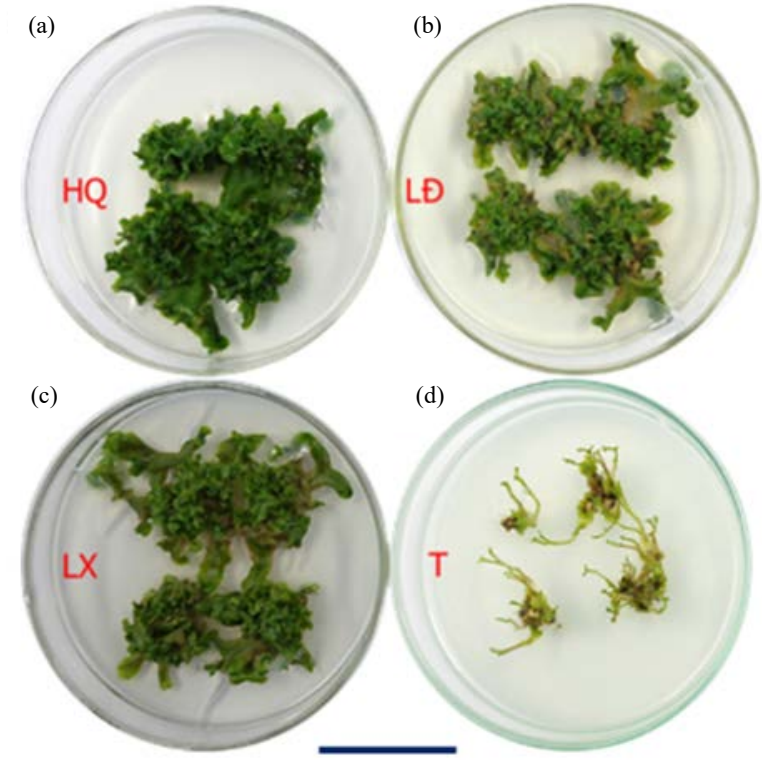

Fig. 5(a-d): In vitro Marchantia polymorpha L. developed under different lighting conditions including (a) White fluorescent (HQ), (b) Red-LED (LĐ), (c) BlueLED (LX) and (d) Dark (T)

Bar: $5 \mathrm{~cm}$

Table 4: Biomass of Marchantia polymorpha L. in different lighting conditions

\begin{tabular}{lcc}
\hline Type of lighting & Fresh weight $(\mathrm{g})$ & Dry weight $(\mathrm{g})$ \\
\hline White fluorescent & $4.83 \pm 0.48^{\mathrm{a}}$ & $0.19 \pm 0.00^{\mathrm{b}}$ \\
Red-LED $(660 \mathrm{~nm})$ & $3.79 \pm 0.18^{\mathrm{b}}$ & $0.18 \pm 0.00^{\mathrm{b}}$ \\
Blue-LED $(454 \mathrm{~nm})$ & $4.91 \pm 0.40^{\mathrm{a}}$ & $0.21 \pm 0.02^{\mathrm{a}}$ \\
In dark & $0.15 \pm 0.01^{\mathrm{c}}$ & $0.02 \pm 0.00^{\mathrm{c}}$ \\
\hline
\end{tabular}

Different letters in one column presents significant differences at the level of $\mathrm{p}<0.05$

Table 5: Fresh and dry biomass of the thallus on the culture medium supplemented tryptone with different concentrations

\begin{tabular}{lcc}
\hline Tryptone concentration $\left(\mathrm{g} \mathrm{L}^{-1}\right)$ & Fresh weight $(\mathrm{g})$ & Dry weight $(\mathrm{g})$ \\
\hline 0 & $2.09 \pm 0.48^{\mathrm{c}}$ & $0.05 \pm 0.02^{\mathrm{d}}$ \\
0.1 & $2.88 \pm 0.60^{\mathrm{c}}$ & $0.08^{\mathrm{c}} \pm 0.02^{\mathrm{c}}$ \\
0.5 & $4.49 \pm 0.62^{\mathrm{b}}$ & $0.12 \pm 0.01^{\mathrm{b}}$ \\
1.0 & $3.88 \pm 0.05^{\mathrm{b}}$ & $0.11 \pm 0.00^{\mathrm{b}}$ \\
1.5 & $5.88 \pm 0.29^{\mathrm{a}}$ & $0.16 \pm 0.01^{\mathrm{a}}$ \\
\hline Different letters in one column presents significant differences at the level of
\end{tabular}
$\mathrm{p}<0.05$

concentrated in midrib regions. Apical notches and immature tissue regions mobilize more sucrose than mature tissue regions, but still ensure the balance of sucrose density in tissue regions. The evidence suggests that the M. polymorpha can also absorb, transport and metabolize sucrose for the development process similar to the vascular plants.

Effect of lighting conditions in cultivation: The biomass of M. polymorpha in different lighting conditions and the morphology was shown in Table 4 and Fig. 5 . In fresh biomass, fluorescent light and blue LED showed no statistically significant difference, greater than red LED with average biomass of 4.83 and $4.91 \mathrm{~g}$, respectively. The results of the dry biomass of the blue LED were greatest in the treatments, with a mass of $0.21 \mathrm{~g}$. Morphological observations shown that, in lighting treatments, the thallus developed well with extended scattering and spreading. In red LED, the thallus was more yellowish brown than that of other treatments. Meanwhile, in the dark, the thallus developed into long, narrow, thin with light green and had the lowest biomass. Obviously, light is essential for the growth and development of this liverwort.

Each type of light has different effects on the morphology and development of plants ${ }^{28}$. Red light $(660 \mathrm{~nm})$ is able to stimulate plant growth, accelerate cell division and stimulate spores. In addition, exposure to red light for too long will cause chlorophyll degradation, which explains the color of the thallus when cultured under red LED light ${ }^{29,30}$. Meanwhile, blue light $(450 \sim 455 \mathrm{~nm})$ has other effects on plants such as affecting the opening of the stomata to impact indirectly the respiration of the plant, helping absorb the mineral and nutrient and stimulating the total increase proteins, pigments and soluble organic compounds ${ }^{31,32}$. Phytochrome-receptors for red light in $M$. polymorpha have been reported by Nishihama et al. ${ }^{33}$. Reports of blue light receptors in this species have not been found. However, the zeaxanthin pigment, a type of blue-light absorbing molecule, has been shown in the chemical composition of this species ${ }^{34}$. The results show that blue light from LEDs has a good effect on the biomass of M. polymorpha. Therefore, blue LED light is the chosen factor to complement in the modified culture process.

Effect of tryptone concentration: The biomass and morphological results of the thallus were presented in Table 5 and Fig. 6. The experiment was conducted to investigate the effect of tryptone on the biomass increase of M. polymorpha. The results in Table 5 show that the increase in tryptone concentration in the medium led to the biomass accumulation of thallus. The tryptone concentration of $1.5 \mathrm{~g} \mathrm{~L}^{-1}$ gave the highest fresh and dry biomass accumulation of 5.88 and $0.16 \mathrm{~g}$, respectively. Moreover, in 1 and $1.5 \mathrm{~g} \mathrm{~L}^{-1}$ tryptone of culture medium treatments, the thallus developed better and greener than the other. In the non-supplemented tryptone treatment, the thallus clusters were yellowish and poorly developed.

Previously, according to Ono et a $/ . .^{35}$ casamino acid was used in the cell suspension culture process of Marchantia polymorpha L. In this study, casamino acid was replaced with tryptone. Both of tryptone and casamino acid are products of casein hydrolysis, when added to the medium that will provide the amino acids as an organic nitrogen source. 


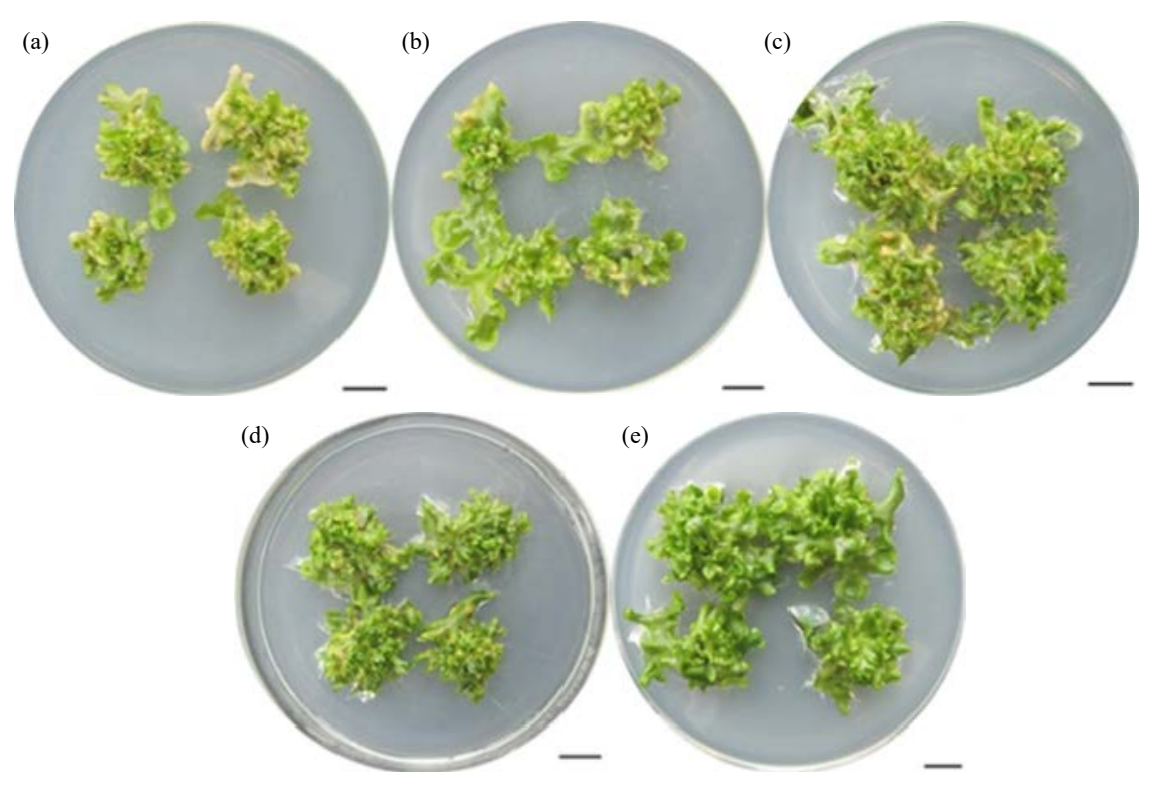

Fig. 6(a-e): Thallus developed in medium with different levels of tryptone concentrations ( $\left.\mathrm{g} \mathrm{L}^{-1}\right)$, Corresponds to, (a) 0 , (b) 0.1, (c) 0.5 , (d) 1 and (e) $1.5 \mathrm{~g} \mathrm{~L}^{-1}$ Bar: $1 \mathrm{~cm}$

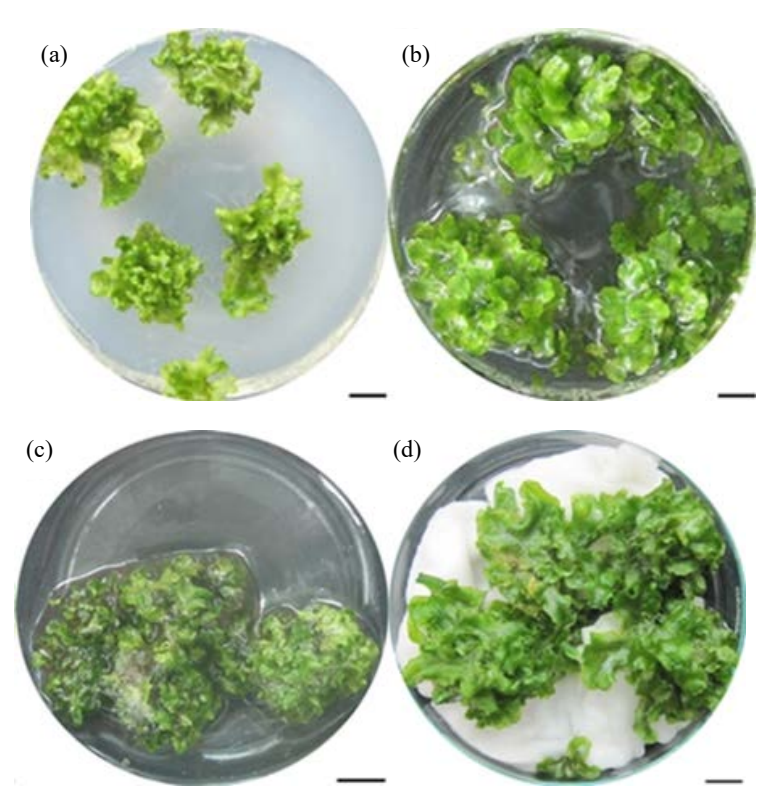

Fig. 7(a-d): Cultured thallus clusters on (a) Solid medium, (b) Liquid medium, (c) Liquid medium with shaker and (d) Cotton swabs Bars: $1 \mathrm{~cm}$

Besides providing amino acids, the addition of tryptone made thallus to be greener, grow favorable and accumulate biomass. In addition, some studies have shown that the addition of amino acid sources help plants restrict the use of

ATP for the conversion of $\mathrm{NH}_{4}{ }^{+}$to amino acids ${ }^{18,21,36}$. Therefore, the presence of amino acids in the environment may help the plant to save number of ATPs.

Effect of types of substrate in cultivation: Water plays an important role in the life of plants. In particular, because the body structure is thin and lacking in cuticle layers, mosses need a lot of water and moisture to help them survive and develop under dehydration. Types of cultivation are also involved in the uptake of water and nutrients in in vitro plant culture. Therefore, this experiment was conducted to evaluate the effects of cultivation types on the biomass accumulation of M. polymorpha.

The data in Table 6 shows that the fresh weight of all treatments was not significantly different. The highest dry biomass yield was $0.18 \mathrm{~g}$ obtained from the cultivation on cotton swabs and in liquid medium with shaker, which were significantly higher than that of agar. Indeed, the type of culture influences the development of $M$. polymorpha liverwort. The morphological observations show that the thallus cultured in liquid medium and on cotton swabs grown better than culture on the solid medium (added agar). Water flexibility and nutrient uptake of the solid medium were not fluent compared to the other treatments. Meanwhile, on the cotton swab, thallus had more stable growth than the culture in liquid medium with shaker (Fig. 7). Thus, in the laboratory 

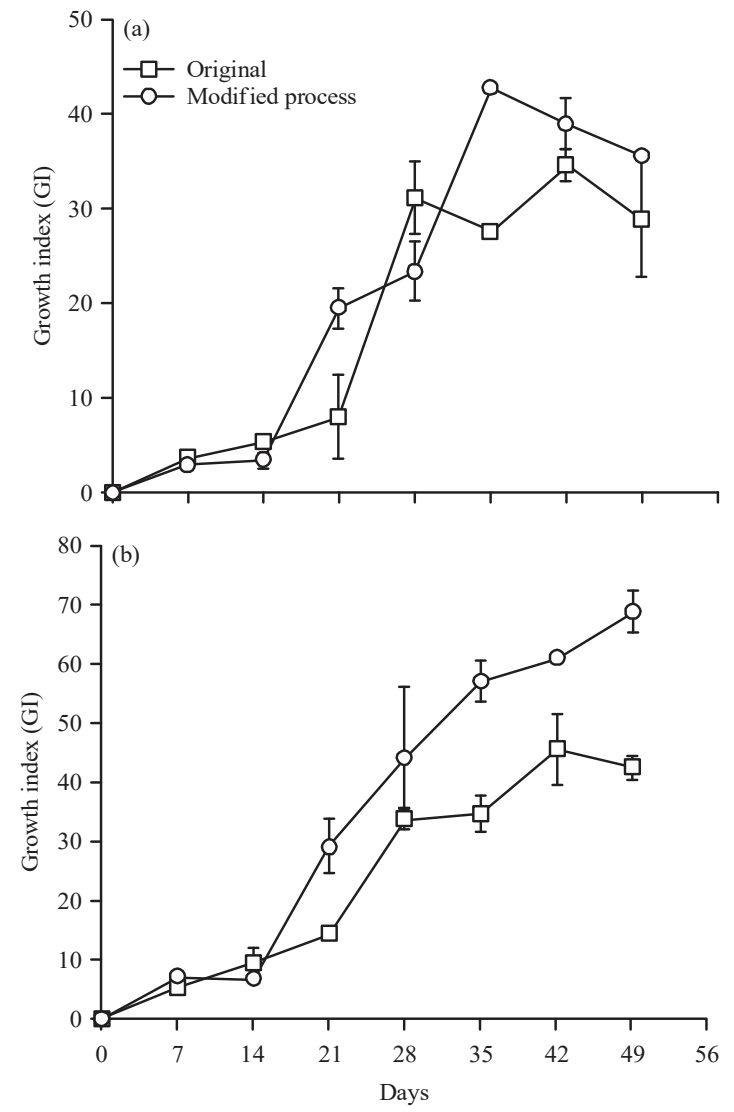

Fig. 8(a-b): Time courses of the Marchantia polymorpha L. growth in original conditions and in modified conditions by the growth index Gl for (a) Fresh weight and (b) Dry weight during the 49 day survey

Table 6: Fresh and dry biomass of liverwort thallus after 6 weeks cultured under different substrate types

\begin{tabular}{lcc}
\hline Types of cultivation & Fresh weight $(\mathrm{g})$ & Dry weight $(\mathrm{g})$ \\
\hline Agar (solid medium) & $3.81 \pm 0.92^{\mathrm{a}}$ & $0.08 \pm 0.02^{\mathrm{b}}$ \\
Cotton swabs & $5.17 \pm 1.66^{\mathrm{a}}$ & $0.18 \pm 0.05^{\mathrm{a}}$ \\
In liquid medium & $4.46 \pm 1.25^{\mathrm{a}}$ & $0.11 \pm 0.04^{\mathrm{ab}}$ \\
In liquid medium (with shaker) & $6.46 \pm 3.03^{\mathrm{a}}$ & $0.18 \pm 0.03^{\mathrm{a}}$ \\
\hline
\end{tabular}

Different letters in one column presents significant differences at the level of $\mathrm{p}<0.05$

scale, M. polymorpha liverwort was cultured on cotton swabs. In industrial scales, culture in liquid without shaker is recommended because of the cost savings and convenience of sample collection.

Effect of combination of independent culture factors on increasing of thallus biomass: Following the results obtained from the independent survey of culture factors, the selected conditions included mineral and vitamin B5 reductions in half (this condition unchanged from the original culture), sucrose at a concentration of $20 \mathrm{~g} \mathrm{~L}^{-1}$ blue LED light $454 \mathrm{~nm}$ with 2300 lux, tryptone added to the medium at $1.5 \mathrm{mg} \mathrm{L}^{-1}$ cultured on cotton swabs. Modified process was established by combining selected elements and replacing the same conditions in the original culture process. Growth curve of two processes according to the $\mathrm{Gl}$ index is shown in Fig. 8.

According to the Gl curve of fresh weight (Fig. 8), at the original process, the adaptive phase lasted for the first 3 weeks of culturing, the growth phase started from day 21-28. Then, stable phase continued with $\mathrm{Gl}$ index ranging from 27.62-34.56 (highest GI index of original culture process). Meanwhile, in the modified process, the adaptive phase was shorter, in the first 2 weeks of culturing. The growth phase started from week 2-5 with the final Gl of 42.73. After that, the $\mathrm{Gl}$ dropped to 35.56 at the end of the survey period.

In the dry biomass index, the $\mathrm{Gl}$ continued to rise at day 35 until the end of the survey period. This result shows that the thallus continued to accumulate biomass. This is quite different from the case of fresh biomass. In particular, the $\mathrm{Gl}$ of the modified medium was significantly higher than that of the original culture medium. At the end of the survey, the Gl of the modified process was 68.74 (with dry biomass obtained $0.54 \mathrm{~g}$ ), higher than that of the original process (with $\mathrm{Gl}$ of 42.40 and dry biomass of $0.33 \mathrm{~g}$ ) with significant difference.

The morphology of the samples at day 49 (Fig. 9) showed the difference between the two treatments. In the original process, the thallus clusters were small in diameter size and the thalli edges were yellow. Appearing brown thalli, indicated that the sample did not develop well at the end of the survey cycle. Meanwhile, in the modified process, the clusters are still developing favorably with expanded thalli, the phenomenon of yellow edges of the thalli only appeared very little.

According to morphological observations and growth index results, the modified culture procedure helped the thallus of M. polymorpha to increase biomass better than the original (improved 1.62 times dry biomass) as well as thalli favorable development. At the end of the survey period, dry biomass may continue to accumulate. Thus, the procedure with modified conditions was used to culture this liverwort for obtaining biomass and serving subsequent biological activity tests. In addition, investigations on the culture process should be continued to select the optimal process.

\section{$\alpha$-Glucosidase inhibition activity of in vitrocultured thallus:}

The four fraction extracts, including n-hexane, chloroform, ethyl acetate and ethanol, were prepared from the dry biomass of the in vitro cultured thallus with modified process in 7 weeks. The extracts were examined for $\alpha$-glucosidase inhibition activity. At a concentration of $1 \mathrm{mg} \mathrm{mL}^{-1}$, all of 
Table 7: $I_{50}\left(\mu \mathrm{g} \mathrm{mL}^{-1}\right)$ of acarbose and four fraction extracts in $\alpha$-glucosidase inhibition activity

\begin{tabular}{llllll}
\hline Sample & Acarbose & n-hexane & Chloroform & Ethyl acetate & Ethanol \\
\hline \hline$C_{50}\left(\mu \mathrm{g} \mathrm{mL}^{-1}\right)$ & $530.88 \pm 140.20^{\mathrm{a}}$ & $11.89 \pm 2.01^{\mathrm{e}}$ & $20.39 \pm 2.93^{\mathrm{d}}$ & $84.25 \pm 27.46^{\mathrm{c}}$ & $361.40 \pm 77.30^{\mathrm{b}}$ \\
\hline Different letters in one row presents significant differences at the level of $\mathrm{p}<0.05$ & &
\end{tabular}
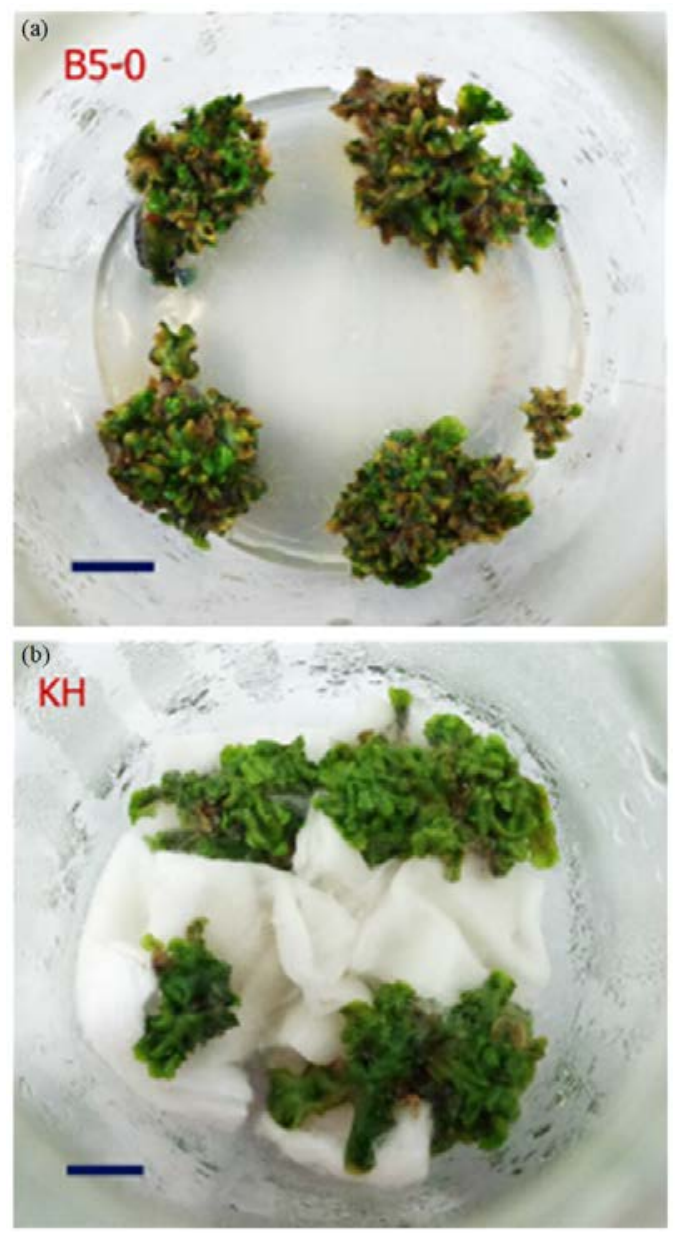

Fig. 9(a-b): Marchantia polymorpha L. Cultured at day 49 (end of survey period) in (a) Original process (B5-0) and (b) Modified process (KH)

Bars: $1 \mathrm{~cm}$

extracts gave the percentage of inhibition greater than or equal to $100 \%$. In addition, to compare the activity of extracts, $\mathrm{IC}_{50}$ was determined by setting the extract concentration ranges decreasing from $1-0 \mathrm{mg} \mathrm{mL}^{-1}$. The results are presented in Table 7.

The data in Table 7 shows that the $I C_{50}$ values of four extracts were lower than that of Acarbose-positive control, suggesting that the $\alpha$-glucosidase inhibition activity of four extracts were stronger than that of positive control. Moreover, the n-hexane fraction was found to be the most active fraction with an average $\mathrm{IC}_{50}$ value of $11.89 \mu \mathrm{g} \mathrm{mL}-1$, about 44 times lower than that of Acarbose.
Inhibition of $\alpha$-glucosidase activity is an important factor in assessing the potential application of a substance for type-2 diabetes treatment. Besides, the inhibitory activity of $\alpha$-glucosidase is also closely associated with the anti-obesity'. Currently, Acarbose is the $\alpha$-glucosidase inhibitor widely used in the treatment of type- 2 diabetes ${ }^{37}$. Besides, studies on the active substance that inhibits this enzyme often focus on vascular plants ${ }^{38,39}$. Meanwhile, studies on $\alpha$-glucosidase inhibitory activity from non-vascular plants are very limited. One of the biggest obstacles in the research process is the source of biomass from wild habitat, which makes it difficult to investigate the several activities with many different species. According to the reports of Harinantenaina and Asakawa ${ }^{40}$ among bis(benzyls) found in liverworts, Marchantin $\mathrm{C}$ is the most potent inhibitor of this enzyme. This is the first report of $\alpha$-glucosidase inhibition from non-vascular plants. In this experiment, the results showed that the in vitro cultured M. polymorpha also contained potential inhibitors for this enzyme. Strong active compounds concentrated in the non-polarization to weak polarization phase, including $\mathrm{n}$-hexane and chloroform fractions. These extracts are going to be investigated and separated to find compounds that could be used in the treatment of type- 2 diabetes.

\section{CONCLUSION}

This study shows that the biomass of Marchantia polymorpha $\mathrm{L}$. liverwort can be obtained through in vitro culture as a raw material source for studies on the biologically active and secondary metabolites. Through experiments, the culture conditions were suitable for the biomass increase of $M$. polymorpha including: half-strength B5 medium supplemented with $20 \mathrm{~g} \mathrm{~L}^{-1}$ sucrose, $1.5 \mathrm{~g} \mathrm{~L}^{-1}$ tryptone and this liverwort was culturing on cotton swabs with liquid medium, under blue LED light ( $454 \mathrm{~nm}$ ). When improved factors were combined, in vitro dry biomass increased by 1.62 times compared to the primary culture conditions.

\section{SIGNIFICANCE STATEMENT}

This study discovered the culture factors including complexes of salts and vitamins of medium, sugar, light, cultivation substrates and tryptone, all influenced the in vitro biomass growth of Marchantia polymorpha L. Thereby, these 
results will support the process to expand the culture scale of this species, it can be beneficial to provide a sufficiently large amount of stable material for serving the active substance studies. Moreover, the results of the $\alpha$-glucosidase inhibitory activity survey also show the biological activity potential of this material. This study will help the researchers to uncover the critical areas of Marchantia polymorpha liverwort cultured in vitro that many researchers were not able to explore. Thus a new insight on this species may be arrived at.

\section{ACKNOWLEDGMENTS}

This study is funded by Vietnam National University Ho Chi Minh City (VNU-HCM) under grant number C2017-18-20. We thank Department of Ecology and Evolutionary Biology, Faculty of Biology, University of Science, Vietnam National University-Ho Chi Minh City for authenticating nature liverwort sample. We thank Research Center for Hi-Tech Application in Agriculture- the RCHAA Center, affiliated with the University of Sciences (VNU-HCM), for providing LED lighting systems in our experiments.

\section{REFERENCES}

1. Asakawa, Y. and A. Ludwiczuk, 2013. Bryophytes: Liverworts, Mosses and Hornworts: Extraction and Isolation Procedures. In: Metabolomics Tools for Natural Product Discovery: Methods and Protocols, Roessner, U. and D.A. Dias (Eds.). Humana Press, Totowa, NJ., USA., ISBN: 978-1-62703-577-4, pp: 1-20.

2. Chandra, S., D. Chandra, A. Barh, Pankaj, R.K. Pandey and I.P. Sharma, 2017. Bryophytes: Hoard of remedies, an ethno-medicinal review. J. Tradit. Complement. Med., 7: 94-98.

3. Asakawa, Y., M. Toyota, M. Tori and T. Hashimoto, 2000. Chemical structures of macrocyclic bis(bibenzyls) isolated from liverworts (Hepaticae). Spectroscopy, 14: 149-175.

4. Dey, A. and A. Mukherjee, 2015. Therapeutic potential of bryophytes and derived compounds against cancer. J. Acute Dis., 4: 236-248.

5. Asakawa, Y. and A. Ludwiczuk, 2017. Chemical constituents of bryophytes: Structures and biological activity. J. Nat. Prod., 81: 641-660.

6. Furness, S.B. and J.P. Grime, 1982. Growth rate and temperature responses in bryophytes: I. An investigation of Brachythecium rutabulum. J. Ecol., 70: 513-523.

7. Shimamura, M., 2016. Marchantia polymorpha: Taxonomy, phylogeny and morphology of a model system. Plant Cell Physiol., 57: 230-256.
8. Drobnik, J. and A. Stebel, 2015. Central European medicinal bryophytes in the 16th-century work by Caspar Schwenckfeld and their ethnopharmacological origin. J. Ethnopharmacol., 175: 407-411.

9. Ludwiczuk, A. and Y. Asakawa, 2008. Distribution of terpenoids and aromatic compounds in selected Southern Hemispheric liverworts. Fieldiana Bot., 47: 37-58.

10. Tanaka, M., T. Esaki, H. Kenmoku, T. Koeduka and Y. Kiyoyama et al., 2016. Direct evidence of specific localization of sesquiterpenes and marchantin $A$ in oil body cells of Marchantia polymorpha L. Phytochemistry, 130: 77-84.

11. Friederich, S., U.H. Maier, B. Deus-Neumann, Y. Asakawa and M.H. Zenk, 1999. Biosynthesis of cyclic bis(bibenzyls) in Marchantia polymorpha. Phytochemistry, 50: 589-598.

12. Keseru, G.M. and M. Nogradi, 1995. The chemistry of macrocyclic bis(bibenzyls). Nat. Prod. Rep., 12: 69-75.

13. Chiyoda, S., K. Ishizaki, H. Kataoka, K.T. Yamato and T. Kohchi, 2008. Direct transformation of the liverwort Marchantia polymorpha L. by particle bombardment using immature thalli developing from spores. Plant Cell Rep., 27: 1467-1473.

14. Ishizaki, K., M. Mizutani, M. Shimamura, A. Masuda, R. Nishihama and T. Kohchi, 2013. Essential role of the E3 ubiquitin ligase nopperabo1 in schizogenous intercellular space formation in the liverwort Marchantia polymorpha. Plant Cell, 25: 4075-4084.

15. Gamborg, O.L., R.A. Miller and K. Ojima, 1968. Nutrient requirements of suspension cultures of soybean root cells. Exp. Cell Res., 50: 151-158.

16. Murashige, T. and F. Skoog, 1962. A revised medium for rapid growth and bio assays with tobacco tissue cultures. Physiol. Planta., 15: 473-497.

17. White, P.R., 1963. The Cultivation of Animal and Plant Cells. 2nd Edn., Ronald Press Co., New York, USA., ISBN-13: 978-0826093806, Pages: 228.

18. Salehi, M., A. Moieni and N. Safaie, 2017. A novel medium for enhancing callus growth of hazel (Cory/us avellana L.). Scient. Rep., Vol. 7. 10.1038/s41598-017-15703-z.

19. Trusheva, B., D. Trunkova and V. Bankova, 2007. Different extraction methods of biologically active components from propolis: A preliminary study. Chem. Cent. J., Vol. 1. 10.1186/1752-153X-1-13.

20. Hogan, S., L. Zhang, J. Li, S. Sun, C. Canning and K. Zhou, 2010. Antioxidant rich grape pomace extract suppresses postprandial hyperglycemia in diabetic mice by specifically inhibiting alpha-glucosidase. Nutr. Metab., Vol. 7. 10.1186/1743-7075-7-71.

21. Bhatia, S., 2015. Plant Tissue Culture. In: Modern Applications of Plant Biotechnology in Pharmaceutical Sciences, Bhatia, S., K. Sharma, R. Dahiya and T. Bera (Eds.). Chapter 2, Elsevier Inc., New York, USA., ISBN: 978-0-12-802221-4, pp: 68-86. 
22. Trang, N.T.H. and L.T.T. Tien, 2012. High frequency shoot regeneration of dark Blue statice (Limonium sinuatum L. Mill) by combining phytohormones with adenine in in vitro culture. J. Biol., 34: 219-226.

23. Igawa, T., Y. Hoshino and M. Mii, 2002. Efficient plant regeneration from cell cultures of ornamental statice, Limonium sinuatum Mill. In vitro Cell. Dev. Biol.-Plant, 38: 157-162.

24. Voth, P.D. and K.C. Hamner, 1940. Responses of Marchantia polymorpha to nutrient supply and photoperiod. Bot. Gazette, 102: 169-205.

25. Wang, J., Y. Zhou, C. Dong, Q. Shen and R. Putheti, 2009. Effects of $\mathrm{NH}_{4}{ }^{+}-\mathrm{N} / \mathrm{NO}_{3}{ }^{-}-\mathrm{N}$ ratios on growth, nitrate uptake and organic acid levels of spinach (Spinacia oleracea L.). Afr. J. Biotechnol., 8: 3597-3602.

26. Shirdel, M., A. Motallebi-Azar, S. Masiha, N. Mortazavi, M. Matloobi and Y. Sharafi, 2011. Effects of inorganic nitrogen source and $\mathrm{NH}_{4}^{+}: \mathrm{NO}_{3}{ }^{-}$ratio on proliferation of dog rose (Rosa canina). J. Med. Plants Res., 5: 4605-4609.

27. Rota, J.A. and N.C. Maravolo, 1975. Transport and mobilization of ${ }^{14} \mathrm{C}$-sucrose during regeneration in the hepatic, Marchanti polymorpha. Bot. Gazette, 136: 184-188.

28. Williams, M., 2012. Evolutionary and developmental origins of leaves. Plant Cell, 21: 1-6.

29. Nakazato, T., A. Kadota and M. Wada, 1999. Photoinduction of spore germination in Marchantia polymorpha L. is mediated by photosynthesis. Plant Cell Physiol., 40: 1014-1020.

30. Taiz, L. and E. Zeiger, 2002. Phytochrome and Light Control of Plant Development. In: Plant Physiology, Taiz, L. and E. Zeiger (Eds.). 3rd Edn., Chapter 17, Sinauer Associates Inc., Sunderland, MA., USA., ISBN-13: 978-0878938230, pp: 375-402.
31. Senger, H., 1982. The effect of blue light on plants and microorganisms. Photochem. Photobiol., 35: 911-920.

32. Voskresenskaya, N.P., 1972. Blue light and carbon metabolism. Annu. Rev. Plant Physiol., 23: 219-234.

33. Nishihama, R., K. Ishizaki, M. Hosaka, Y. Matsuda, A. Kubota and T. Kohchi, 2015. Phytochrome-mediated regulation of cell division and growth during regeneration and sporeling development in the liverwort Marchantia polymorpha. J. Plant Res., 128: 407-421.

34. Takemura, M., T. Maoka and N. Misawa, 2014. Carotenoid analysis of a liverwort Marchantia polymorpha and functional identification of its lycopene $\beta$ - and $\epsilon$-cyclase genes. Plant Cell Physiol., 55: 194-200.

35. Ono, K., K. Ohyama and O.L. Gamborg, 1979. Regeneration of the liverwort Marchantia polymorpha L. from protoplasts isolated from cell suspension culture. Plant Sci. Lett., 14: 225-229.

36. Thom, M., A. Maretzki, E. Komor and W.S. Sakai, 1981. Nutrient uptake and accumulation by sugarcane cell cultures in relation to the growth cycle. Plant Cell Tissue Org. Cult., 1: 3-14.

37. De Melo, E.B., A.D.S. Gomes and I. Carvalho, 2006. $\alpha$ - and $\beta$-Glucosidase inhibitors: Chemical structure and biological activity. Tetrahedron, 62: 10277-10302.

38. Kumar, S., S. Narwal, V. Kumar and O. Prakash, 2011. $\alpha$-glucosidase inhibitors from plants: A natural approach to treat diabetes. Pharmacogn. Rev., 5: 19-29.

39. Tundis, R., M.R. Loizzo and F. Menichini, 2010. Natural products as $\alpha$-amylase and $\alpha$-glucosidase inhibitors and their hypoglycaemic potential in the treatment of diabetes: An update. Mini Rev. Med. Chem., 10: 315-331.

40. Harinantenaina, L. and Y. Asakawa, 2007. Malagasy liverworts, source of new and biologically active compounds. Nat. Prod. Commun., 2: 701-709. 